\title{
Basin Modeling in Complex Area: Examples from Eastern Venezuelan and Canadian Foothills
}

\author{
F. Schneider ${ }^{1}$ \\ 1 Institut français du pétrole, 1 et 4, avenue de Bois-Préau, 92852 Rueil-M almaison C edex - France \\ e-mail: frederic.schneider@ifp.fr
}

\begin{abstract}
Résumé - Modélisation de bassin en zones complexes : exemples des piémonts vénézuéliens et canadiens - L'objectif de la modélisation de bassin est de reconstruire l'histoire géologique d'un bassin sédimentaire et de ses systèmes pétroliers afin de pouvoir prédire l'existence d'accumulations. Les modèles de bassin prennent en compte la compaction, les transferts de chaleur, la génération des hydrocarbures et la circulation des fluides. Cependant, les modèles de bassin classiques ne sont pas utilisables dans les zones de piémont où la géométrie est complexe. C'est pour répondre à ce besoin que le prototype Ceres a été développé. Ce prototype est capable de simuler dans une section 2D des écoulements triphasiques pour un bassin dont la géométrie évolue au cours du temps sous l'effet de la sédimentation, de la compaction, des érosions, de la tectonique salifère et des déplacements des blocs le long des failles.

Une étude est généralement constituée de trois étapes principales. La première consiste à construire la section à l'époque actuelle. Ceci est généralement effectué à partir de l'interprétation sismique, des données de puits, des observations d'affleurements et des analyses de carottes. Durant cette étape, la section est généralement équilibrée en utilisant un logiciel tel que Locace.
\end{abstract}

La seconde étape consiste à la restauration de la section. La section à l'époque actuelle est restaurée progressivement dans le passé pour chacune des couches définies jusqu'à ce que le substratum soit atteint. Pour équilibrer les sections au cours du temps et pour contraindre les parties érodées, il est parfois nécessaire d'utiliser un logiciel cinématique direct comme Thrustpack. Ce prototype nous permet alors de construire des sections intermédiaires consistantes d'un point de vue cinématique.

La troisième étape est consacrée aux simulations directes. Pour résoudre les équations utilisées dans les modèles de bassins, nous avons dû développer des méthodes numériques originales qui mettent en œuvre des techniques de décomposition de domaines.

La méthodologie précédente est le fruit de tests effectués sur une coupe en Alberta (Canada) et une autre au Venezuela. Si l'on considère l'origine des fluides dans les grès d'âge Oligocène de la structure de El Furrial ou bien dans les dolomies d'âge Mississippien des piémonts canadiens, on reconnaît un épisode commun d'expulsion de fluides le long de la stratification. Avant la phase de flexure et de chevauchement, les fluides sont essentiellement expulsés vers la surface sous l'effet de la compaction. Ensuite, à cause de la flexure et des chevauchements, les fluides sont poussés le long de la stratification avec des vitesses qui atteignent plusieurs dizaines de kilomètres par million d'années. Cet épisode d'expulsion de fluide s'arrête à un endroit donné quand les failles deviennent actives en cet endroit. 


\begin{abstract}
Basin Modeling in Complex Area: Examples from Eastern Venezuelan and Canadian
Foothills - Basin modeling aims at reconstructing the time evolution of a sedimentary basin in order to make quantitative predictions of geological phenomena leading to hydrocarbons accumulations. It accounts for porous medium compaction, heat transfer, hydrocarbon generation and fluid flow. Nevertheless, classical basin models handle simple geometry and are not usable in complex geometry area such as foothills. This is why, a numerical prototype Ceres, has been developed. This prototype is able to model three-phase flow in a $2 D$ section of a basin, whose geometry changes through time accounting for deposition, compaction, erosion of the sediments, salt or mud creeping, and block displacement along faults.

The classical flow chart to perform a case study is composed of three main steps. The first step is the building of the present day section. This is generally done with data coming from the seismic interpretation, wells, outcrops, and core data. At this stage, the section is generally balanced using software such as Locace.

The second step is the restoration of the section. The section at present day is restored back in the past for each of the defined layer until the substratum is reached. In order to balance the section during time and to constrain the eroded parts of the section, we have to use a forward kinematic modeling tool such as Thrustpack. Thus, from a section restored with Locace before thrusting, the use of Thrustpack allows to construct intermediate sections during time, which are consistent from a kinematics point of view.

The last step is the forward simulation. And, in order to solve the coupled equations that are generally used in basin models, we had to develop original numerical methods based on domain decomposition techniques.

The previous methodology is the fruit of tests performed for an Alberta (Canada) transect and an eastern Venezuelan transect. When considering the origin of the fluids in the Oligocene sandstones of the El Furrial structure or in the Mississipian dolomite of the Canadian foothills, a general scenario of squeegee fluids is recognized. Before the flexuring and thrusting period, fluids are in equilibrium with the sediments. They are being continuously expelled toward the surface during the compaction related dewatering. Then, because of the tilting and thrusting with the deposition of synflexural sediments, an episode of squeegee fluid is created with flow along the stratification that can reach velocity of tens of kilometers per million of years. This squeegee episode stops when the thrusts of the considered area become active.
\end{abstract}

\section{IN TRO DUCTIO N}

Basin modeling aims at reconstructing the time evolution of a sedimentary basin in order to make quantitative predictions of geological phenomena leading to pressure generation and hydrocarbons accumulations. It accounts for porous medium deformation, heat transfer, hydrocarbon formation and migration (e.g. Schneider et al., 2000b).

Since the pioneer works on the modeling of hydrocarbon formation (Tissot, 1969), several generation of basin model were built. First 1D model such as Genex were used to simulate the temperature evolution and the maturation of the organic matter. In sedimentary basin context, the 1D approach is satisfactory for these purposes because the thermal transfers are mostly vertical. Indeed, thermal convective transfers are most frequently negligible. Then $2 \mathrm{D}$ model such as Temispack (Doligez et al., 1986; Ungerer et al., 1990) were built. These 2D models provide the possibilities of performing an evaluation of the pressure history and appreciating the hydrocarbon migration and reservoir filling. However, these evaluations can only be qualitative because fluid (water, oil, and gas) migration is mainly convective and therefore sensitive to 3D geometry and anisotropy. For these reason, a generation of 3D basin model was designed such as Temis3D (Schneider et al., 2000b).

The previous sedimentary basin models are able to handle relatively simple geometries resulting from deposition, erosion and vertical compaction. But, as the exploration is now focussing in area such as foothills, a new generation of models able to handle faults was needed.

This is why the Ceres project was launched. The aim of this project was to build a prototype that is able to model three-phase flow in a 2D section of a basin, whose geometry changes through time accounting for deposition, compaction, erosion of the sediments, salt or mud creeping, and block displacement along faults.

In the first part of the paper, Ceres is presented according to the classical workflow used to perform case studies. The second part of the paper is dedicated to a quick review of some cases performed with Ceres.

\section{CERES PRO TO TYPE}

The software is composed of several modules. The main modules are a section editor, a restoration module and a 
forward simulation simulator. The other modules are a chronostratigraphy editor, a lithology editor, a kerogen editor, fluid editors, a mesh editor, a run editor, and visualization modules. A study browser manages all these modules.

The main steps to carry out a case study are:

- the edition of the initial section;

- the restoration of the section;

- the forward simulations.

\subsection{Edition of the Initial Section}

The initial section is composed of a chronostratigraphic column and a 2D cross section. In the study browser, the root of a tree represents this first composite object. The number of horizons, the corresponding number layers, the ages of the horizons, and the values of the eustatism level are edited with the chronostratigraphic editor.

The section can be edited directly from scratch or its geometry can be imported from other softwares. It is recommended, at this stage to use structural software such as Locace (Moretti et al., 1988; Moretti and Larrere, 1989) that is able to balance the section. The edition of the section is split into three steps (Schneider et al., 2002b). First, the geometry of the section is defined. Second, the geological attributes are affected. These attributes may be horizon, fault, section boundary, facies change limit. At this stage a decollement level is defined by superimposing a horizon with a fault. At the end of this second step, the section is filled with the lithologies. The third step of the edition of the section, is the numerical step. At this stage, the blocks, which represent the smallest kinematics units, are defined. Then, each of the blocks is meshed. One specificity of the gridding is that each block holds its own grid with no constraint coming from the other blocks. The faults are not gridded in the initial section because their grids are created dynamically during the forward simulation.

The initial section (Fig. 1), once edited, holds the upper mantle, the ductile lower crust, the brittle upper crust and the considered sedimentary part. The faults can exist in the sediments and in the brittle upper crust; they may be rooted at the interface of the brittle upper crust with the ductile lower crust or at predefined decollement levels.

\subsection{Restoration of the section}

Once the edition of the initial section is terminated, a backward process, which includes a kinematics restoration, backstripping, and thickness modification, allows determining the input data for the forward calculator. During the backward process all the periods defined in the chronostratigraphic column should be restored. For this step, it is recommended, especially for complex area, to use a structural forward model such as Thrustpack (Deville and
Sassi, 1996; Sassi et al., 1998) in order to constrain the geometry through time and to provide a reliable estimation of the eroded parts. At the study browser level, a branch of the tree represents a restoration scenario from the initial section to the final section, only composed of the basement. Each leaf of the branch is a section at the corresponding age. For each restoration, the backward process is composed of different steps (Schneider et al., 2002b).

The first step is the edition of the eroded parts if erosion has occurred during the considered period. Importing templates may help this edition. The second step is an automatic popping of the section. It allows taking off what has been sedimented during the considered period. Once the erosion and the sedimentation accounted for, the resulting section is decompacted using porosity depth relationships.

The backstripped section is then restored from a kinematics point of view. At this stage, the displacements along faults are accounted using translations and vertical shear. As for the edition of the eroded parts, this operation may be constrained with the use of templates.

Once the section is restored, the last step of the backward process is the thickness modifications. This step allows accounting for salt or mud tectonics. Correction of the edition of the erosion may be done at this stage. Nevertheless, the main use of this editor is to account for thickness modifications due to salt tectonics or mud creeping.

These steps should be performed for each layer initially defined in the section at present day. The result is a scenario of restoration (Fig. 2) that should be validated against the previous structural study.

\subsection{Forward Simulations}

In these complex geometries, faults cut the basin into blocks that naturally define computational subdomains. In the blocks, the model accounts for the porous medium compaction, erosion, heat transfer, hydrocarbon formation and migration (Schneider et al., 2002b). The equations are mass conservation of solid and fluids (water, oil and gas) coupled with the Darcy's law and a compaction law. The faults have a constant thickness and their permeability may evolve with time. The prototype allows using three permeability models for the faults: faults may be impervious, pervious or may have a permeability that is a function of the neighboring lithologies and of the strain rate.

In order to solve the three-phase flow in a basin cut by faults along which block displacements can occur, Domain Decomposition Methods (DDM) are used (Willien et al., 1998a, 1998b). The classical techniques used in the first version have been improved by using optimized interface conditions (Faille et al., 2002). In these methods, the faults are considered as subdomains with their own geological properties. However, because of the very small width of the 


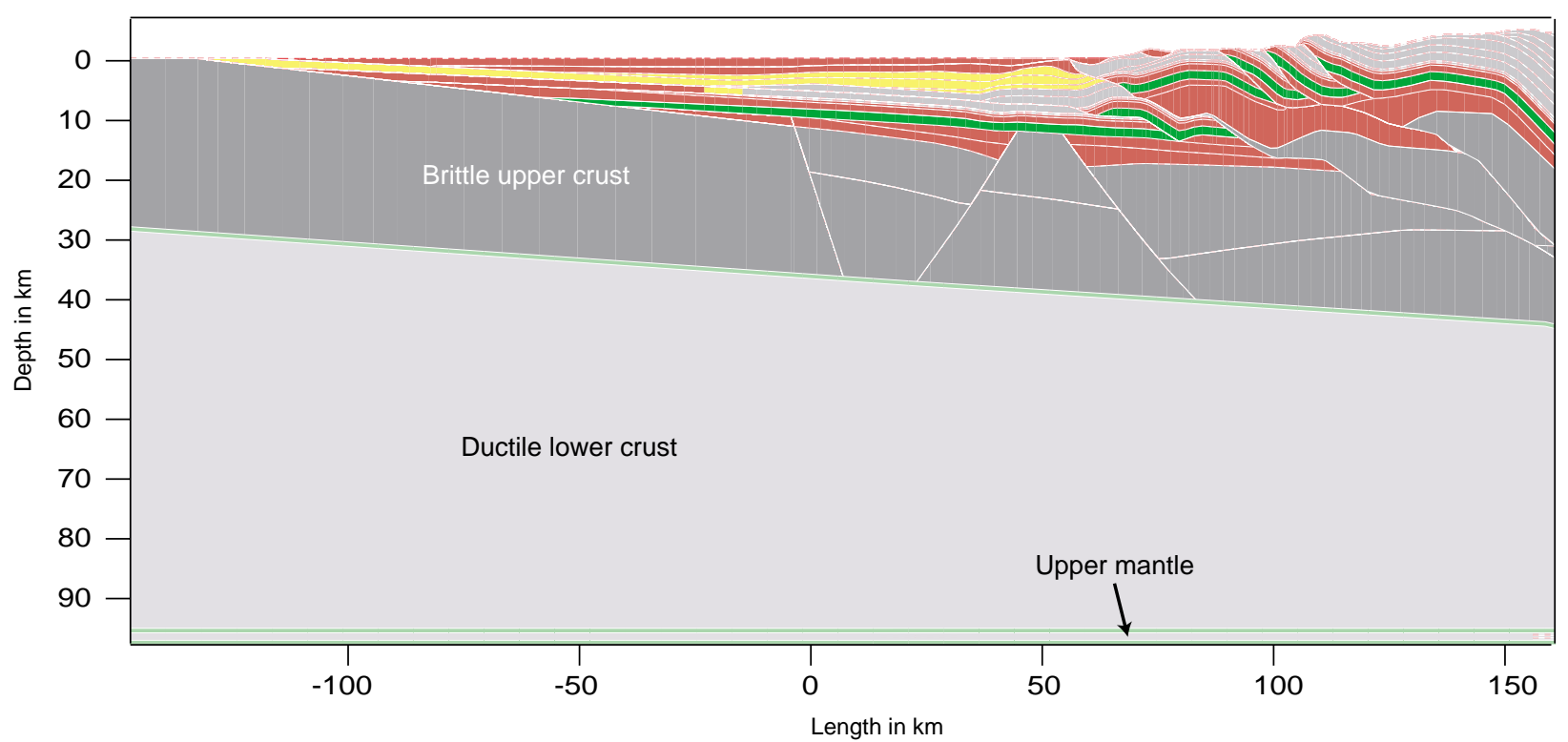

\begin{tabular}{|l|}
\hline $\begin{array}{l}\text { Run: El Furrial 12 } \\
\text { Age: } 0 \text { Ma }\end{array}$ \\
\hline Lithology \\
\hline Sandstone \\
Source rock \\
Marl \\
Silt \\
Shaly silt \\
Silty shale \\
Shale \\
Upper crust \\
Lower crust \\
\hline$\square$
\end{tabular}

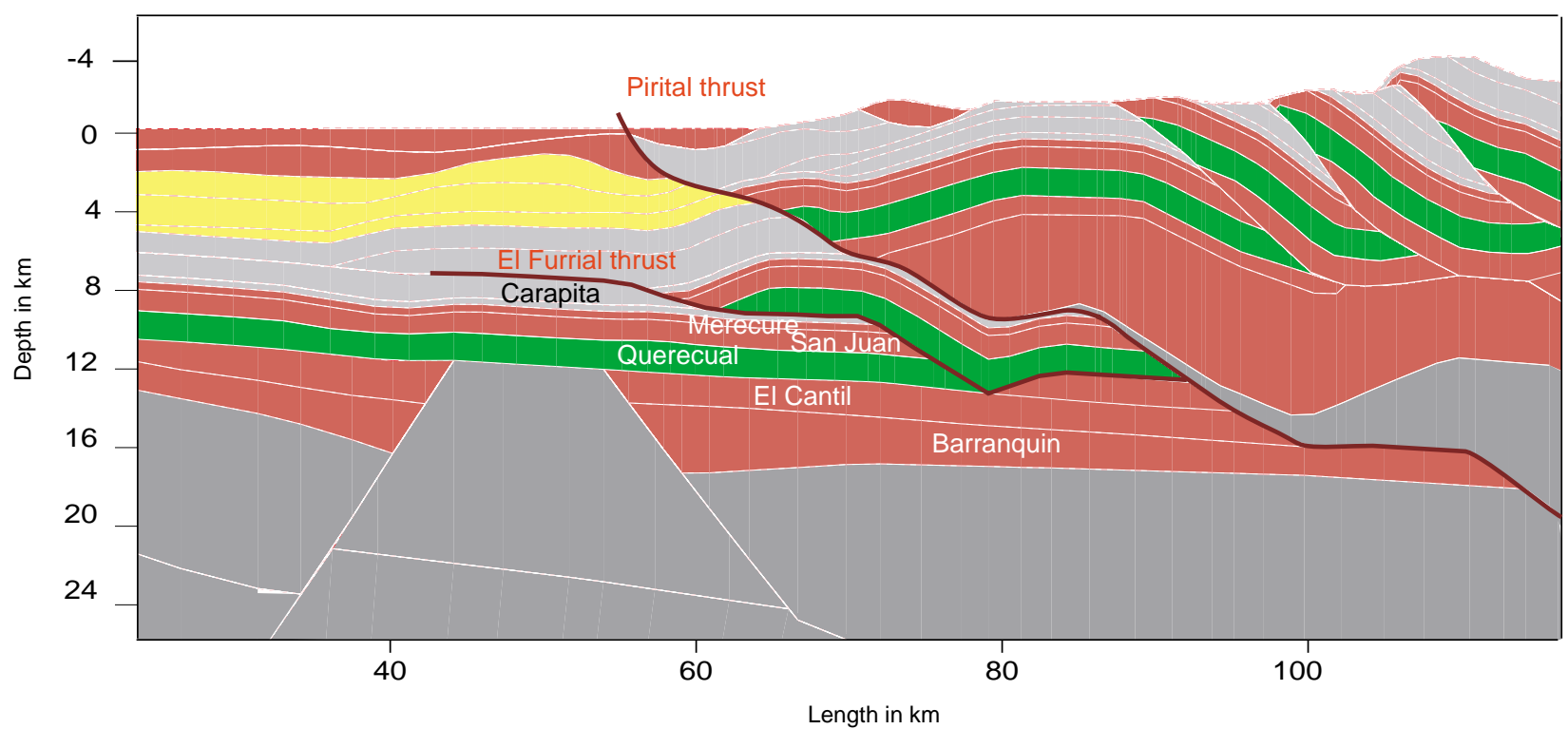

Figure 1

Geometry and lithology distribution of the Venezuelan section at present day. This section shows the ductile lower crust, the brittle upper crust with some faults rooted at the interface. In the upper part of the section are the "sediments". The upper mantle, used for the thermal simulation is not represented. The white dot indicates the El Furrial structure. 
65.0 Ma (passive margin stage)

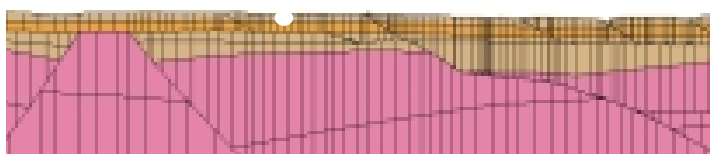

$22.5 \mathrm{Ma}$ (onset of foreland flexure and tilting)

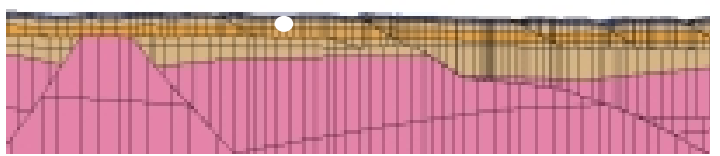

$20.0 \mathrm{Ma}$

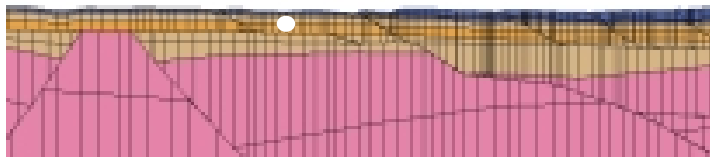

$17.5 \mathrm{Ma}$

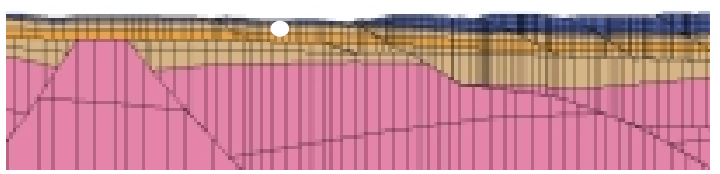

15.0 Ma (onset of thrusting)

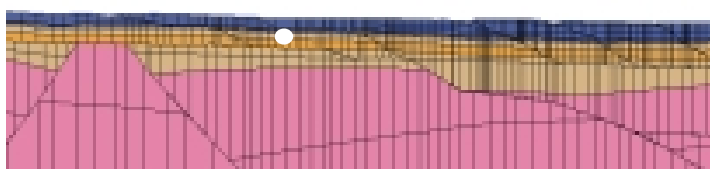

$12.0 \mathrm{Ma}$

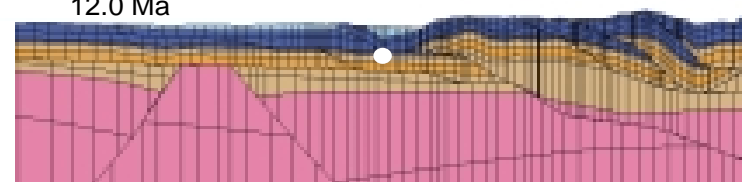

10.0 Ma

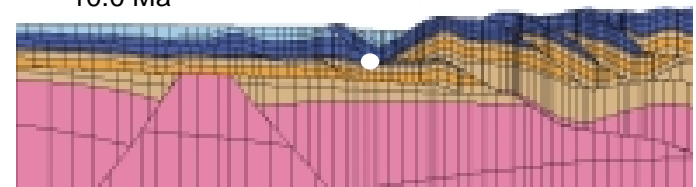

$7.5 \mathrm{Ma}$

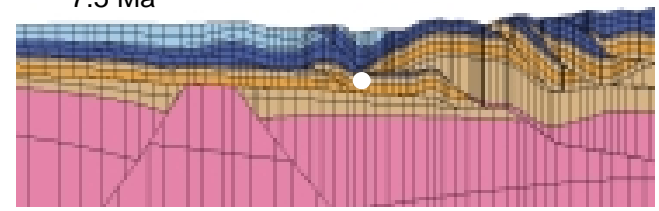

$5.0 \mathrm{Ma}$

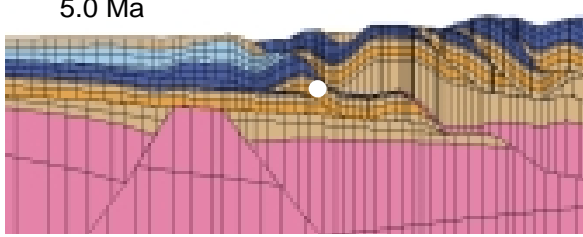

$0.0 \mathrm{Ma}$

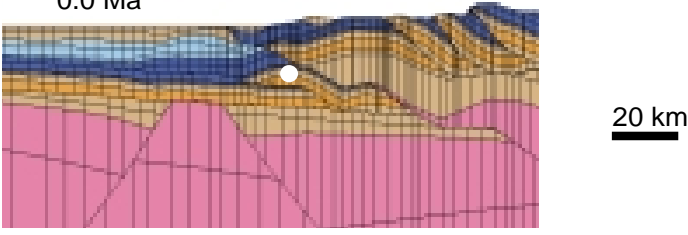

Figure 2

Geometrical evolution of the section from $-65 \mathrm{Ma}$ to present day. The flexure and the tilting of the foreland begins at $22.5 \mathrm{Ma}$. The thrusting begins at $15 \mathrm{Ma}$. The white dot indicates the El Furrial structure.

faults in comparison with the size of the basin, we are studying another approach where the faults are characterized as interfaces between blocks (Faille et al., accepted). In all the cases, the equations are discretized using a cell-centered finite volume scheme in space. Finite volume methods are known to be robust and cheap methods for the discretization of conservation laws in heterogeneous media and have the important property to be conservative.

Different time discretizations coupled with several DDM algorithms have been tested. In a first stage, a classical IMPES scheme (Implicitly advances the Pressure and Explicitly updates the Saturation in time) was used. But, it is well known that this scheme needs time step limitations for stability reasons. In order to use larger time steps, we have tested (Flauraud et al., 2000) a sequential scheme, called IMPIMS (Implicitly advances the Pressure and Implicitly advances the Saturation in time). It consists in solving two nonlinear systems, one for the pressure (as in the IMPES scheme) and one for the saturation.

\section{CASE STUDIES}

This prototype has now been used to study petroleum systems all around the world. In the Bolivian foothills were faults are supposed to be the most important carrier beds for hydrocarbon migration. This prototype was used to perform a sensitivity study on fault permeability (Schneider et al., 1999). In the Congo offshore, it was used to study the impact of faulting on maturity of the organic matter and hydrocarbon migration (Schneider et al., 1999). In the Gulf of Mexico, it was tested for studying the impact of the timing of salt withdrawal on hydrocarbon migration (Schneider et al., 2000a).

More recently, Ceres was tested within the frame of the IFP subtrap consortium in thrust area such as the Canadian foothills and the eastern Venezuelan foothills (Schneider et al., 2001, 2002a). The prototype has been used to quantify the fluid flow and to reconstruct the pore fluid history of the subthrust reservoirs. The use of Ceres implies a backward restoration. Although the backward restoration is fully 
appropriate for modeling an extensional basin well balanced, it may turn difficult to constrain successive intermediate evolutionary stages, as far as the topography (prediction of erosion) and thrust geometry are concerned. In consequence, we have decided to use also the Thrustpack forward kinematic software to elaborate a better structural scenario. These successive intermediate geometries were then used as templates for the Ceres modeling.

\subsection{Venezuelan Transect}

As defined previously, the first task to perform at the beginning of a Ceres study is the definition of the initial section (Fig. 1). This was done with data coming from the seismic interpretation, well data, field data, and core data.
Then, the available data and the Thrustpack scenario have been used to build the Ceres dataset.

From the available data, it is clear that the El Furrial structure (e.g. Parnaud et al., 1995) is closed today as it is overpressured while the equivalent layers of the southern part have nearly hydrostatic pressures.

The El Furrial trend from the eastern Venezuelan transect displays two distinct episodes of quartz cementation. The first generation of quartz overgrowths, which account for more than $90 \%$ of the cements, is developed during the active dewatering processes in the Oligocene strata of the underthrust foreland. This is evidenced by the $\delta^{18} O$ signature and by the Ceres fluid flow simulations (Schneider et al., 2001, submitted). In contrast, the second generation of quartz overgrowths displays quite distinct $\delta^{18} O$ values (Schneider
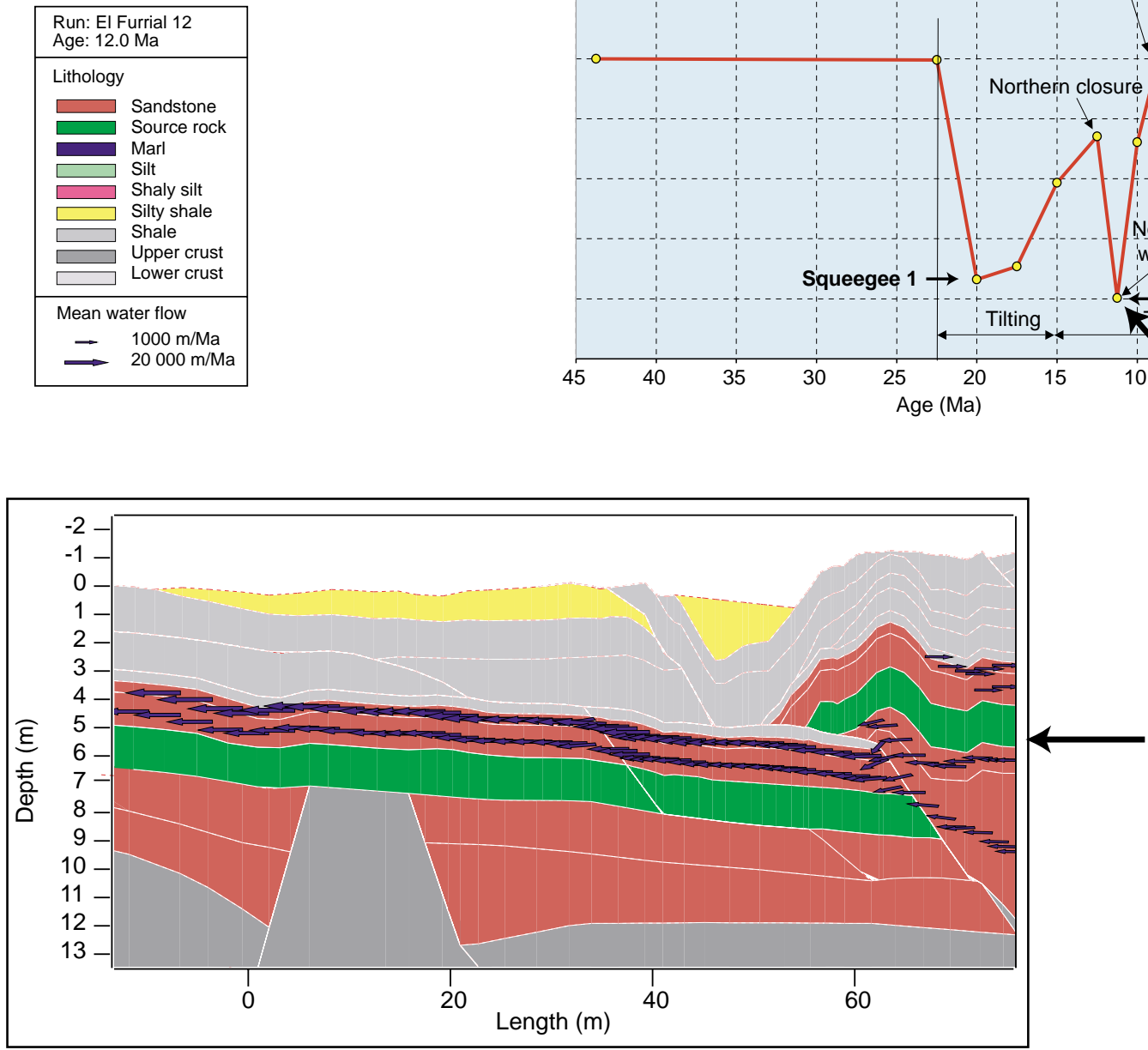

Figure 3

Computed fluid velocity evolution along the stratification in the Oligocene sandstones from the El Furrial structure. The evolution is characterized by two squeegee episodes. The first one is related to the beginning of the tilting. The second one is due to thrusting that allows the fluids to communicate between the Cretaceous sandstones and the Oligocene sandstones.
Northern opening with Cretaceous 


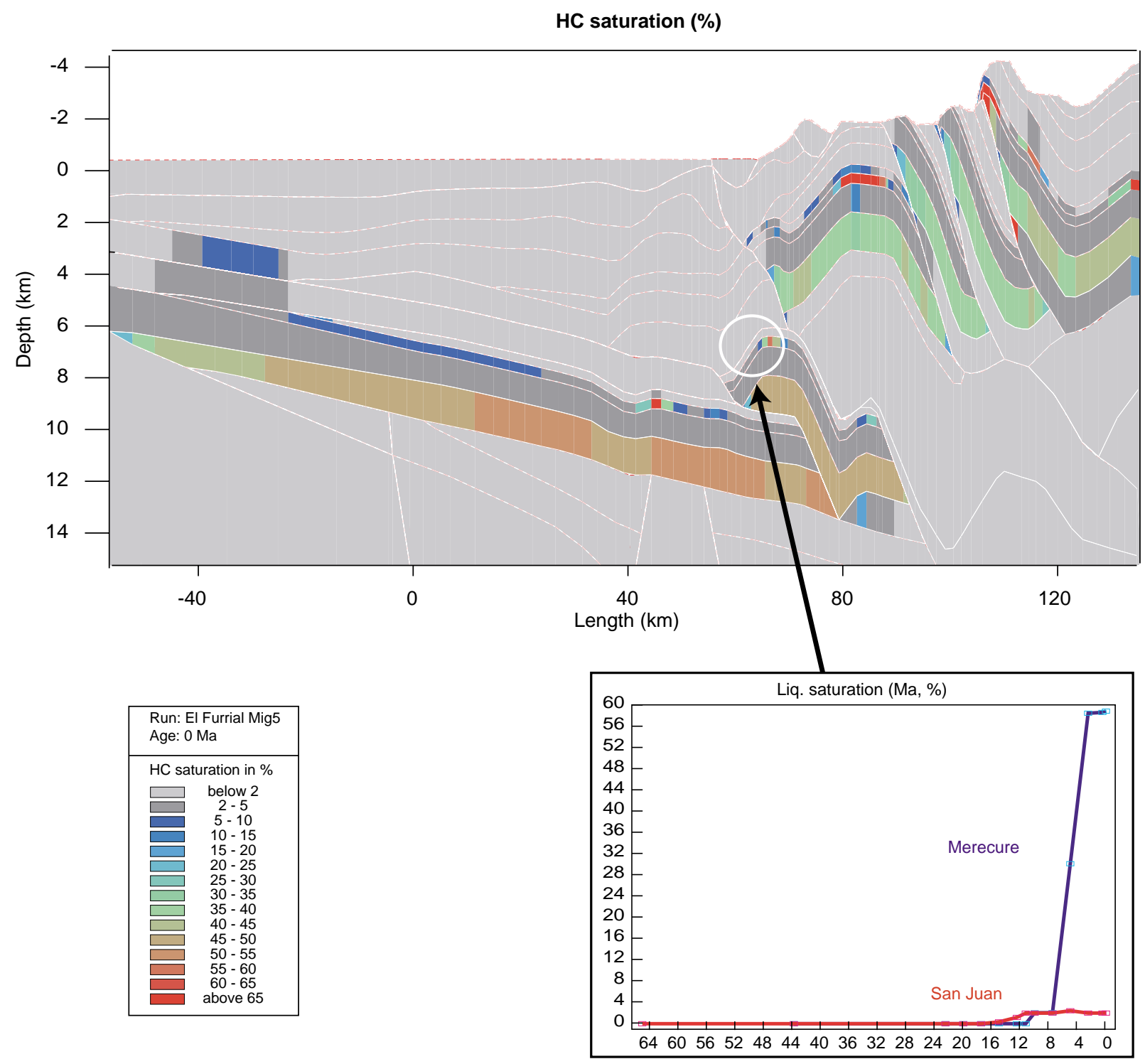

Figure 4

Computed hydrocarbon saturation at present day for the Venezuelan section. The computed evolution of the oil saturation shows that the hydrocarbons begins to flow $12 \mathrm{Ma}$ ago. The filling of the reservoir is correlated with the creation of the El Furrial structure and more precisely with the southern closure of the structure.

et al., submitted). These cements are originated when the deeper aquifer of the Lower Cretaceous Barranquin formation from the Pirital hanginwall started to expel its fluids towards the Oligocene reservoir of the adjacent El Furrial footwall unit. This is well evidenced by the Ceres fluid flow simulations (Fig. 3).

When considering the origin of the fluids in the late Cretaceous-Oligocene sandstone reservoirs of the El Furrial structure, four steps should be considered (Fig. 3).
- From -65 to -20 Ma: fluids were at thermal equilibrium with the sediments. They were continuously expelled vertically toward the surface during compaction-driven dewatering processes.

- From -20 to -12 Ma: as a result of the regional flexuring and tilting and the deposition of the synflexural Naricual Formation, the Oligocene sandstones of the El Furrial structure became efficient conducts for fluids circulating from the north. These fluids (squeegee 1 in Fig. 3) were at 


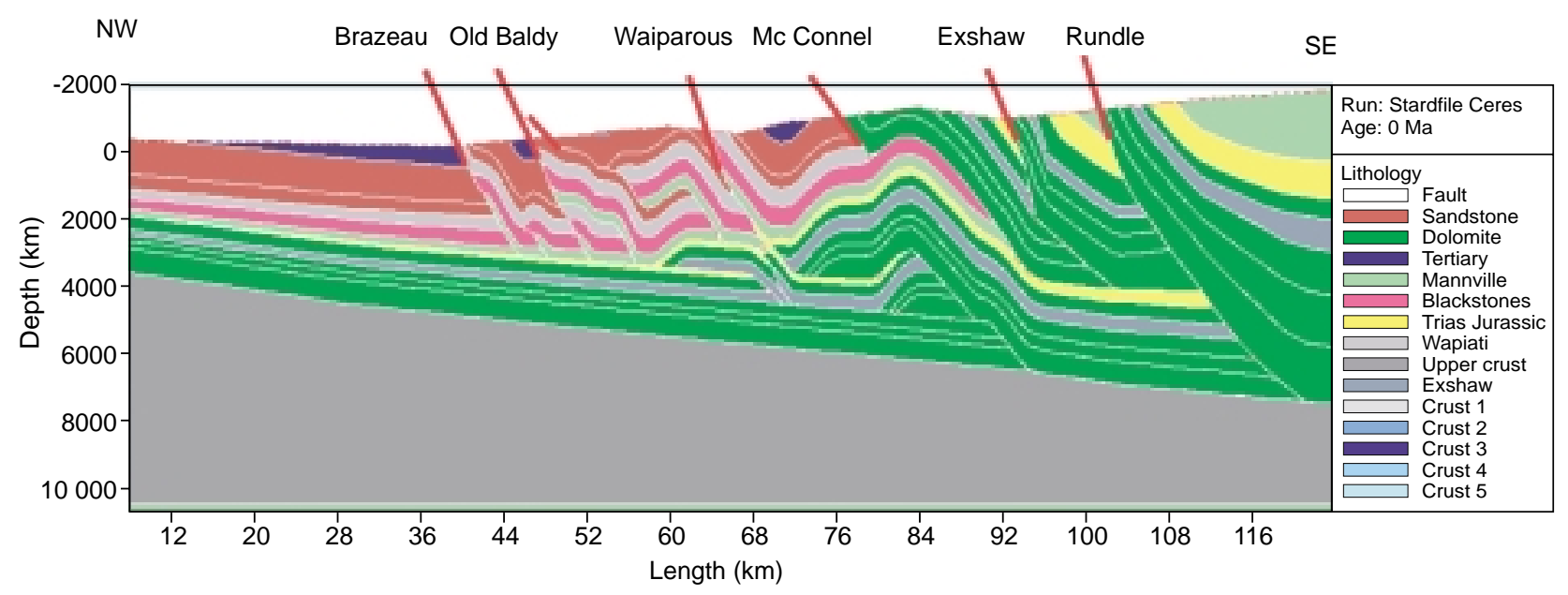

Figure 5

Geometry and lithology distribution of the Canadian section at present day. This section shows the main thrust. The main source rock is the Exshaw formation. The mains reservoirs are located in the Mississipian dolomites.

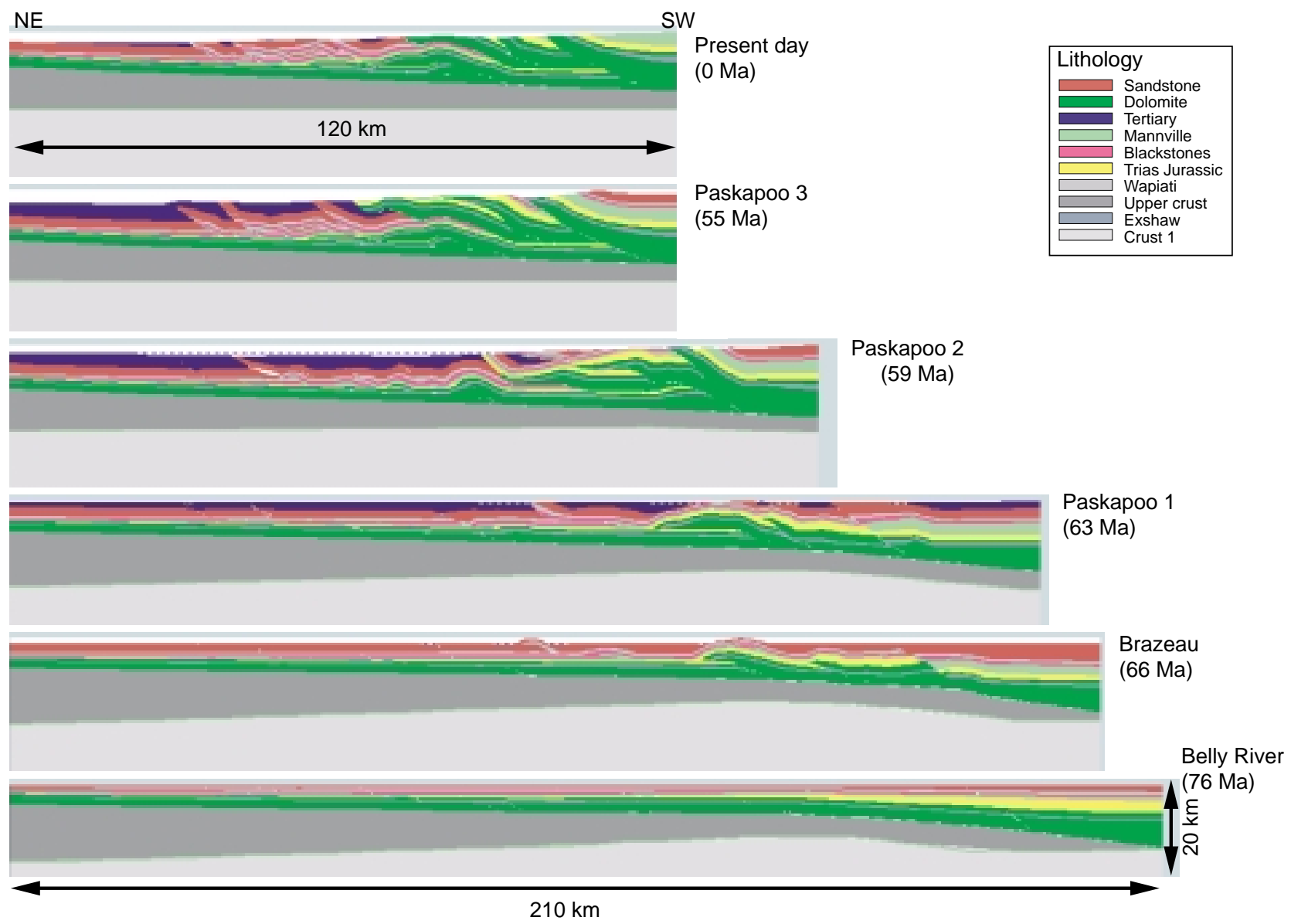

Figure 6

Geometrical evolution of the Canadian section from -76 Ma to present day. In this scenario, the flexure and the tilting begins at 76 Ma. The thrusting begins at $66 \mathrm{Ma}$. 

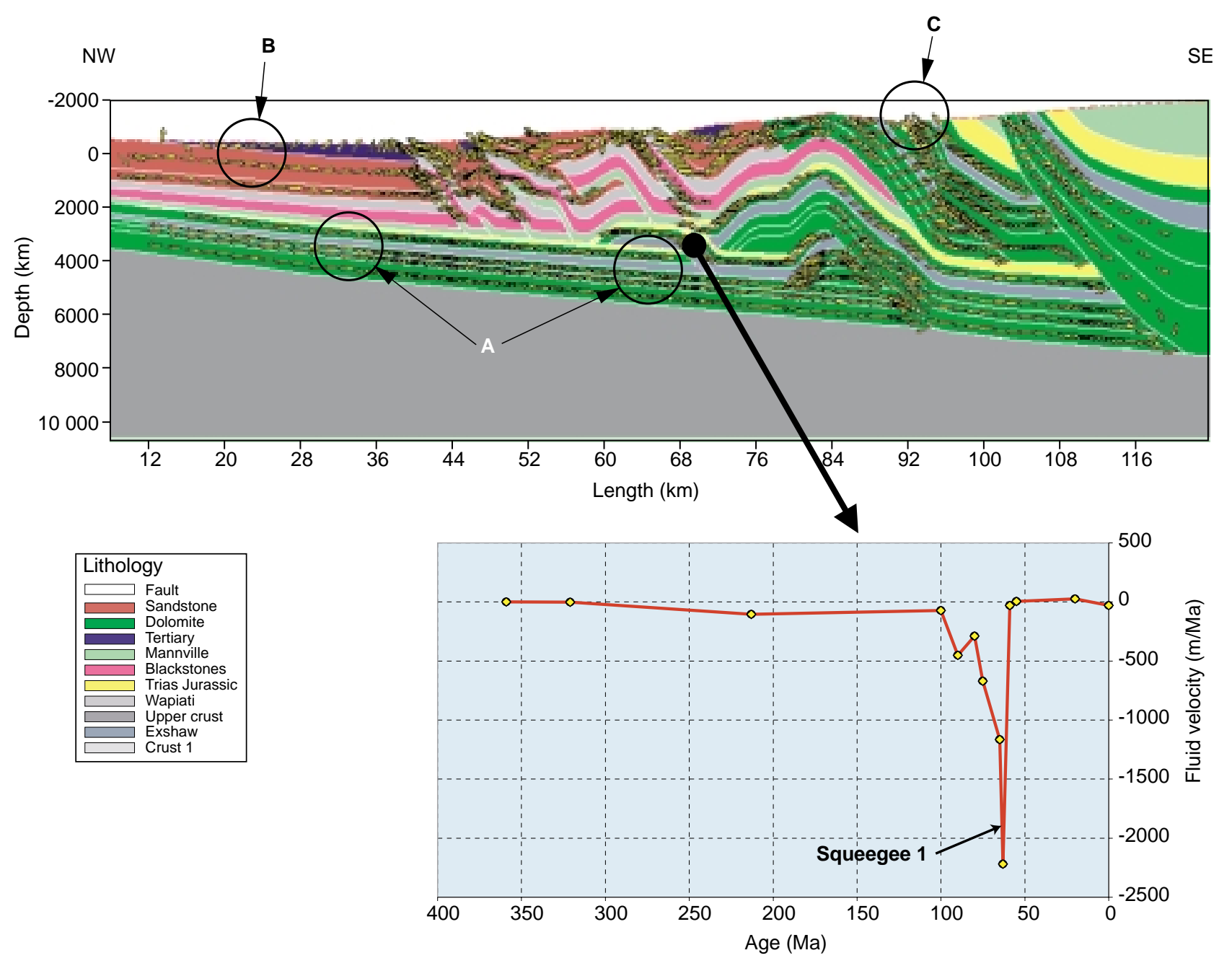

Figure 7

Canadian section at present day showing the computed fluid flow. A: water flow toward the NW; B: water flow toward the SE; C: simulated "hot springs". The diagram below shows the fluid velocity evolution for the Mississipian reservoir. One of the characteristics of this evolution is the squeegee episode related to the flexure and the tilting period.

thermal equilibrium with the Oligocene sandstones in the north, but recorded higher temperatures than adjacent sediments in the El Furrial area. The average Darcy velocity of these fluids decreased from 20 to $5 \mathrm{~km} / \mathrm{Ma}$.

This episode is characterised by an increase of the overpressure in the Oligocene and Upper Cretaceous sandstones correlated with a hydraulic fracturing of the sealing Carapita black shales.

- From -12 to $-8 \mathrm{Ma}$ : from the Ceres model, due to the tectonic accretion, deeper sedimentary units (e.g. early Cretaceous series) were in contact with shallower units (e.g., Oligocene and late Cretaceous series), giving rise to an exchange and mixture of fluids (Squeegee 2 in Fig. 3) with different temperatures and compositions, that probably resulted in additional, but minor, episodes of quartz precipitation. This hypothesis is consistent with the information obtained from oxygen isotope analyses, which suggest that subsequent generations of quartz cement probably formed from evolved basinal fluids.

- A reduction of the intensity of the flow and then an inversion of this flow mark the sealing of the southern structural closure of the structure at around $-8 \mathrm{Ma}$. Then the closure of the northern flank occurs at around $-5 \mathrm{Ma}$ as indicated by a present velocity of the fluids close to zero in the El Furrial reservoirs.

The hydrocarbons filling history shown in Figure 4 is consistent with the fluid inclusion studies, which show that hydrocarbons were present during the quartz cementation of the San Juan formation but they were not present during the quartz cementation of the Merecure formation. 

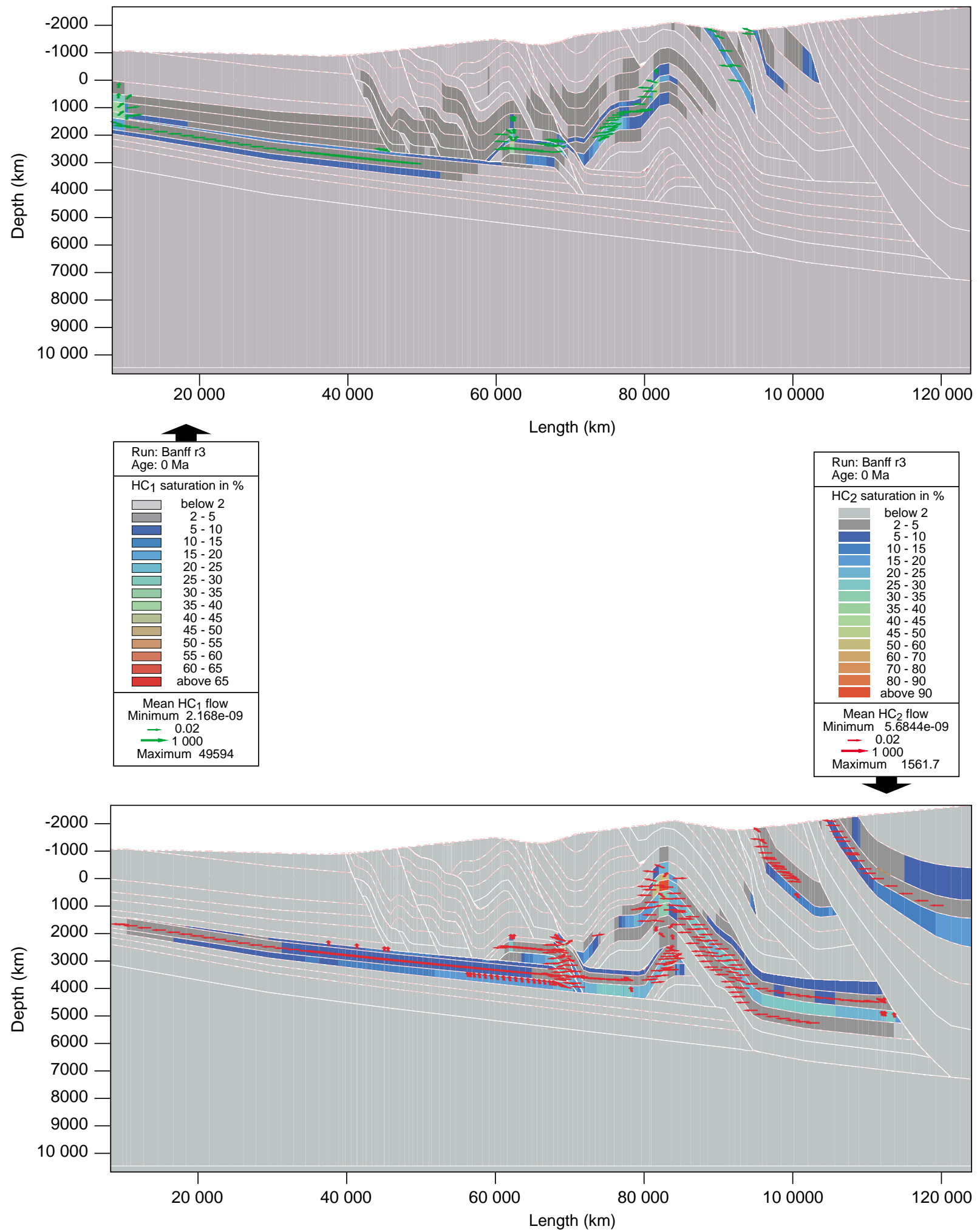

Figure 8

Computed hydrocarbon saturation at present day for the Canadian section. $\mathrm{HC}_{1}$ means oil and $\mathrm{HC}_{2}$ means gas. 


\subsection{Canadian Transect}

As for the Venezuelan transect, the first work to perform at the beginning of a Ceres study is the definition of the initial section (Fig. 5). Then, one scenario for the geometry evolution has been defined (Fig. 6). It is characterized by five major episodes in the geodynamic evolution:

- pre-flexural deposition during the Paleozoic and Lower Mesozoic times on a Precambrian substratum;

- deposition of synflexural formation from -100 to $-76 \mathrm{Ma}$;

- a main thrusting phase between -76 and $-55 \mathrm{Ma}$;

- a strong erosion from -55 to $-20 \mathrm{Ma}$;

- since -20 Ma the area is uplifted.

Unlike in Venezuela, where modern fluid flow is still controlled by the compressive evolution of the foothills, the Ceres fluid flow simulations shown that a dramatic change occurred since the end of the Laramian Orogeny. Indeed, more than $4 \mathrm{~km}$ of Mesozoic and Cenozoic series have been eroded and the hinterland and the foreland were progressively uplifted. Thus, the present day topography and the geometry of the aquifer (Fig. 7) mainly control fluid flow (Tóth, 1988; Garven, 1989; Bachu, 1999).

When considering the origin of the fluids in the Mississipian dolomite of the area, three steps should be considered (Fig. 7):

- From deposition to -100 Ma: fluids are in equilibrium with the sediments. They are continuously expelled toward the surface during the compaction dewatering.

- From -100 to -63 Ma: because of the tilting and thrusting with the deposition of synflexural sediments, the Mississipian sediments of a considered area will receive fluids from the West with velocity reaching $2 \mathrm{~km} / \mathrm{Ma}$. These fluids are in equilibrium with the Mississipian dolomite at the West and should have higher temperatures than the considered sediments.

- From -59 Ma to present: due to the thrusting, the structure became closed and there is no flow any more.

Figure 8 shows preliminary results concerning hydrocarbon migration in this area. $\mathrm{HC}_{1}$ and $\mathrm{HC}_{2}$ represent respectively oil and gas.

\section{CONCLUSION}

Ceres is a new tool that enables to perform basin modeling in complex area where faults or salt tectonics may constrain the petroleum system. This prototype was tested successfully worldwide. It may now be used to understand petroleum systems in much more complex tectonic environment as the ones generally addressed with classical basin models.

The Ceres software, when coupled with a forward kinematics tool, such as Thrustpack, can be used for the simulation of the very complex structures of the foothills. It can provide reliable values for the velocity of the paleo-fluid circulations and for the paleo-fluid pressure. In the two last case studies performed, it was used to evidence a squeegee phase (call squeegee 1) during the tilting period. For the Venezuelan case study a second phase of squeegee (call squeegee 2) was simulated during the thrusting period.

It should be noticed that for these studies, it was of real importance to work closely with the structural geologists in order to define the initial section and the scenario for the kinematics restoration.

\section{REFEREN CES}

Bachu, S. (1999) Flow Systems in the Alberta Basin; Patterns, Types and Driving Mechanisms. Bulletin of Canadian Petroleum Geology, 47, 4, 455-474.

Deville, E. and Sassi, W. (1996) Thrustpack; un logiciel de modélisation intégrée (cinématique, thermique et géochimique); application aux Alpes nord-occidentales. In L'exploration pétroliere dans les fronts compressifs. Pétrole et Techniques, 401, p.77.

Doligez, B., Bessis, F., Burrus, J., Ungerer, Ph., and Chénet, P.Y. (1986) Integrated Numerical Simulation of Sedimentation, Heat Transfer, Hydrocarbon Formation and Fluid Migration in a Sedimentary Basin: The Temis Model. In Thermal Modeling in Sedimentary Basins, Proceeding of the $1^{\text {st }}$ IFP Research Conference on Exploration, Carcans, June 3-7, 1985, 173-195.

Faille, I., Flauraud, E., Nataf, F., Schneider, F. and Willien, F. (2002) Optimized Interface Conditions for Sedimentary Basin Modeling. In Proceedings of the Thirteenth International Conference on Domain Decomposition Methods, N. Debit, M. Garbey, R. Hoppe, J. Periaux, D. Keyes and Y. Kuznetsov editors, Lyon, France, 2000, 453-460.

Faille, I., Flauraud, E., Nataf, F., Pégaz-Fiornet, S., Schneider, F. and Willien, F. (2002) A New Fault Model in Geological Basin Modelling. Application of a Finite Volume Scheme and Domain Decomposition Methods. Third International Symposium on Finite Volumes for Complex Applications - Problems and Perspectives, June 24-28, 2002, Porquerolles, France.

Flauraud, E., Faille, I., Willien, F., Nataf, F. and Schneider F. (2000) Implicit Scheme and Domain Decomposition Method for Multiphase Flow in Porous Medium. Proceedings of the $7^{\text {th }}$ European Conference on the Mathematics of Oil Recovery (ECMOR VII), Dino Hotel, Italy, 5-8 September.

Garven, G. (1989) A Hydrogeologic Model for the Formation of the Giant Oil Sands Deposits of the Western Canada Sedimentary Basin. American Journal of Science, 289, 2, 105-166.

Moretti, I., Bessis, F., Colletta, B., Cuvillier, T., Larrere, M., Triboulet, S., Letouzey, J., Maisondieu, V., and Werner, P. (1988) Locace Program; A New Tool for Balancing Cross Section. In Mediterranean Basins Conference and Exhibition, AAPG Bulletin, 72, 8, 1015.

Moretti, I. and Larrere, M. (1989) Locace; Computer-Aided Construction of Balanced Geological Cross Sections. Geobyte, 4, 5, 16-24.

Parnaud, F., Gou, Y., Pascual, J.C., Truskowski, I., Gallango, O. and Passalacqua, H. (1995) Petroleum Geology of the Central Part of the Eastern Venezuelan Basin. In Petroleum Basins of South America, Tankard A.J., Soruco R.S. and Welsink H.J. editors, AAPG Memoir, 62, 741-756. 
Sassi, W., Rudkiewicz, J.L., and Divies, R. (1998) New Methods for Integrated Modeling of Deformation and Petroleum Generation in Fold and Thrust Belts. In American Association of Petroleum Geologist 1998 Annual Meeting (abstract).

Schneider, F., Devoitine, H., Faille, I., Flauraud, E. and Willien, F. (1999) A New 2D Basin Modeling Tool for HC Potential Evaluation in Faulted Area. Application to the Congo Offshore and to the Bolivian Sub Andean Zone. AAPG Hedberg Research Conference, Colorado Spring, May 9-13.

Schneider, F., Faille, I., Flauraud E. and Willien, F. (2000a) A 2D Basin Modeling Tool for HC Potential Evaluation in Complex Area. $62^{\text {nd }} E A G E$, Glasgow, May 29-June 2.

Schneider, F., Wolf, S., Faille, I. and Pot, D. (2000b) A 3D-Basin Model for Hydrocarbon Potential Evaluation: Application to Congo Offshore. Oil \& Gas Science and Technology - Revue de l'Institut Français du Pétrole, 55, 1, 3-13.

Schneider, F., Hernández, H. and Roure, F. (2001) Ceres FluidFlow and Pressure Modeling of an Eastern Venezuelan Transect. AAPG Hedberg Conference "New Technologies and New Play Concepts in Latin America”, November 4-9, 2001, Mendoza, Argentina.

Schneider, F., Faure, J.L. and Roure, F. (2002a) Methodology for Basin Modeling in Complex Area: Examples from Eastern Venezuelan and Canadian Foothills. AAPG Hedberg Conference "Deformation History, Fluid Flow Reconstruction and Reservoir Appraisal in Foreland Fold and Thrust Belts”, May 14-18, 2002, Palermo-Mondello, Sicily, Italy.

Schneider, F., Devoitine, H., Faille, I., Flauraud, E. and Willien, F. (2002b) Ceres2D: A Numerical Prototype for HC Potential
Evaluation in Complex Area. Oil \& Gas Science and Technology - Revue de l'Institut Français du Pétrole, 57, 6, 607-619.

Schneider, F., Pagel, M. and Hernandez, E. (submitted) Fluid Flow History and Quartz Cementation in the Eastern Venezuelan Foothill. AAPG Memoir.

Tissot, B. (1969) Premières données sur les mécanismes et la cinétique de la formation du pétrole dans les sédiments. Simulation d'un schéma réactionnel sur ordinateur. Revue de l'Institut Français du Pétrole, 24, 6, 470-501.

Ungerer, Ph., Burrus, J., Doligez, B. and Bessis, F. (1990) Basin Evaluation by Integrated Two-Dimensional Modeling of Heat Transfer, Fluid Flow, Hydrocarbon Generation and Migration. AAPG Bull., 74, 3, 309-335.

Tóth, J. (1988) Ground Water and Hydrocarbon Migration. In The Geology of North America, Back W., Rosenshein J.S. and Seaber P. R. editors, O-2, 485-502.

Willien, F., Faille, I. and Schneider, F. (1998a) Domain Decomposition Methods Applied To Sedimentary Basin Modeling. In Ninth International Conference on Domain Decomposition Methods, P.E. Bjorstad, M.S. Espedal and D.E. Keyes editors, 736-744.

Willien, F., Faille, I., Nataf, F. and Schneider, F. (1998b) Domain Decomposition Methods for Fluid Flow in Porous Medium. Proceedings of the $6^{\text {th }}$ European Conference on the Mathematics of Oil Recovery (ECMOR VI), Peebles, GB, 7-11 September.

Final manuscript received in March 2003 